\title{
Spatial-Temporal Estimation and Analysis of Japan Onshore and Offshore Wind Energy Potential
}

\author{
Rémi Delage *(D), Taichi Matsuoka and Toshihiko Nakata \\ Department of Management Science and Technology, Graduate School of Engineering, Tohoku University, \\ Sendai 980-8579, Japan; taichi.matsuoka.r8@dc.tohoku.ac.jp (T.M.); nakata@tohoku.ac.jp (T.N.) \\ * Correspondence: delage@tohoku.ac.jp
}

\begin{abstract}
In the carbon-neutral scenarios fixed by most developed countries, wind and solar resources play a significant role due to their substantial potential. Their instability can be mitigated through smarter designs of energy systems, including sector coupling and cross-border interconnections, which require detailed information on the spatial and temporal evolution of these intermittent resources. The present study aims at estimating the spatial-temporal energy potential of wind in Japan based on meteorological weather data. These data allow to analyze the potential of resources sharing to reduce power generation's lack and excess, even in such an isolated country due to its variety of climate conditions and local energy demand. The correlation skewness is introduced as a measure of the sites' uniqueness to identify important sites for the spatial distribution of capacity toward the efficient stabilization of supply at a national scale in a model-free fashion.
\end{abstract}

Keywords: wind potential; spatial-temporal analysis; cross-border; Japan

check for

updates

Citation: Delage, R.; Matsuoka, T.;

Nakata, T. Spatial-Temporal Estimation and Analysis of Japan Onshore and Offshore Wind Energy Potential. Energies 2021, 14, 2168. https://doi.org/10.3390/en14082168

Academic Editor: Eugen Rusu

Received: 15 March 2021

Accepted: 11 April 2021

Published: 13 April 2021

Publisher's Note: MDPI stays neutral with regard to jurisdictional claims in published maps and institutional affiliations.

Copyright: (C) 2021 by the authors. Licensee MDPI, Basel, Switzerland. This article is an open access article distributed under the terms and conditions of the Creative Commons Attribution (CC BY) license (https:/ / creativecommons.org/licenses/by/ $4.0 /)$.

\section{Introduction}

The interest in energy systems started in the mid-1970s when modeling was employed for energy planning to respond to the oil crisis [1]. Today, researchers are working on improving our energy systems by solving the trilemma between affordability, security, and environmental sustainability toward a carbon-neutral society in order to mitigate climate change. It is widely accepted that wind and solar resources play a crucial role in decarbonizing energy systems because of their substantial potential, yet they suffer from being highly unstable [2]. Straightforward strategies to integrate these resources include the synchronization of demand with energy generation through demand-side management and price incentives $[3,4]$, or the storage of excess generation, although current electrical batteries are costly and have a non-negligible environmental impact [5]. Other solutions consist of smarter energy systems' designs to improve their efficiency and flexibility through the interconnection of energy sectors on both the supply and demand sides (sector coupling) [6-8], and the cross-border interconnections between countries and regions $[9,10]$. The latter takes advantage of the chaotic nature of air flows resulting in a loss of coherence between air masses as the distance between them increases [11].

Sector coupling and cross-border network analysis and design require detailed and accurate information on the spatial and temporal evolution of energy production and demand, especially when considering the systems' complexity [12] and their evolution toward decentralized systems $[13,14]$. In addition, such data are necessary to the development of machine learning models for the management of energy systems with increasing complexity [15].

While European countries or American states can undoubtedly benefit from the interconnection grid on a large scale for the temporal smoothing of wind and solar energy production, other countries, like Japan, are more isolated and must rely on local energy generations to replace the current importations of fuel resources [16]. Japan offers an interesting case study for multiple reasons in addition to this geographically isolated status. 
It is a developed country with high energy demand due to its high population density; it gathers a variety of environmental conditions resulting in high disparities between regions' energy demand and potential production from local resources; it requires special care for energy systems' resilience because of the frequent and difficultly predictable typhoons and earthquakes, as well as annual heatwaves.

There have been reports on Japan's high wind potential [17], but the lack of nationwide data combining high spatial and time resolution impairs the development and analysis of sector coupling and cross-region solutions. Indeed, studies have so far been limited to either the total potential on large scales, thus ignoring the characteristic intermittent fluctuations of wind, or the potential at small scales with higher temporal resolution from onshore sensors [18]. In particular, the offshore wind potential has only been assessed from the average wind speed [17], in specific regions [19], or from sparse coastal sensors offering poor spatial resolution and questionable far from shore estimations [20].

In an effort to fill this lack of data, the present study uses meteorological data to estimate the onshore and offshore wind energy potential in Japan with a high spatial and temporal resolution following the methodology already applied and accepted in other countries [21,22]. Using the produced data paired with electricity demand data from local power supply companies, we analyze the cross-region interconnecting potential to mitigate generation instabilities. Lastly, we introduce the correlation skewness as a data-driven measure to quantify the sites' importance toward the efficient supply stabilization with limited capacity.

\section{Materials and Methods}

\subsection{Data}

We use the wind $U$ and $V$ velocity components data at $10 \mathrm{~m}$ altitude estimated by the Japan Meteorological Agency Numerical Weather Prediction Meso-scale model [23]. The model provides $39 \mathrm{~h}$ forecasts every $3 \mathrm{~h}$ with a time and spatial resolution of $1 \mathrm{~h}$ and $5 \mathrm{~km}$, respectively. For best accuracy, the data are organized in series of initial values every $3 \mathrm{~h}$, with the intervals between filled with $2 \mathrm{~h}$ of forecast values [24]. Finally, missing data are filled using linear interpolation. MERRA-2 [25] and ERA5 [26] might provide more accurate time estimations but currently have a lower spatial resolution than Japan Meteorological Agency's model.

\subsection{Wind Potential Estimation}

The wind magnitude $v$ in $\mathrm{m} \cdot \mathrm{s}^{-1}$ is first calculated at $10 \mathrm{~m}$ altitude from

$$
v_{10}=\sqrt{U^{2}+V^{2}}
$$

then estimated at a given altitude $h$ in meters using the wind gradient formula

$$
v_{h}=v_{10}\left(\frac{h}{10}\right)^{\alpha}
$$

with $\alpha$ the Hellmann exponent varying with ground terrain shape. The $\alpha$ values used for different land cover types are summarized in Table 1 [27]. We use the land cover data provided by the Japanese Ministry of Land, Infrastructure, Transport, and Tourism [28]. $\alpha$ values are first attributed to each land cover type according to Table 1 , then converted to the wind speed data meshes coordinates using 2-dimensional linear interpolation. Figure 1 shows the resulting $\alpha$ map. The unknown land cover regions correspond to the subtropical Ogasawara islands, which are considered for our analysis. Although the variation of Hellmann exponents is expected [27] with seasonal terrain modifications, such as deciduous trees losing their leaves or snow falls, the exponents are considered constant here. 
Table 1. Considered Hellmann exponents $\alpha$ for different land cover types.

\begin{tabular}{lc}
\hline Land Cover Type & $\alpha$ \\
\hline Water bodies, snow, and ice & 0.1 \\
Grasslands & 0.15 \\
Shrublands & 0.2 \\
Forests & 0.25 \\
Cities with tall buildings & 0.4 \\
Unknown & 0.14 \\
\hline
\end{tabular}

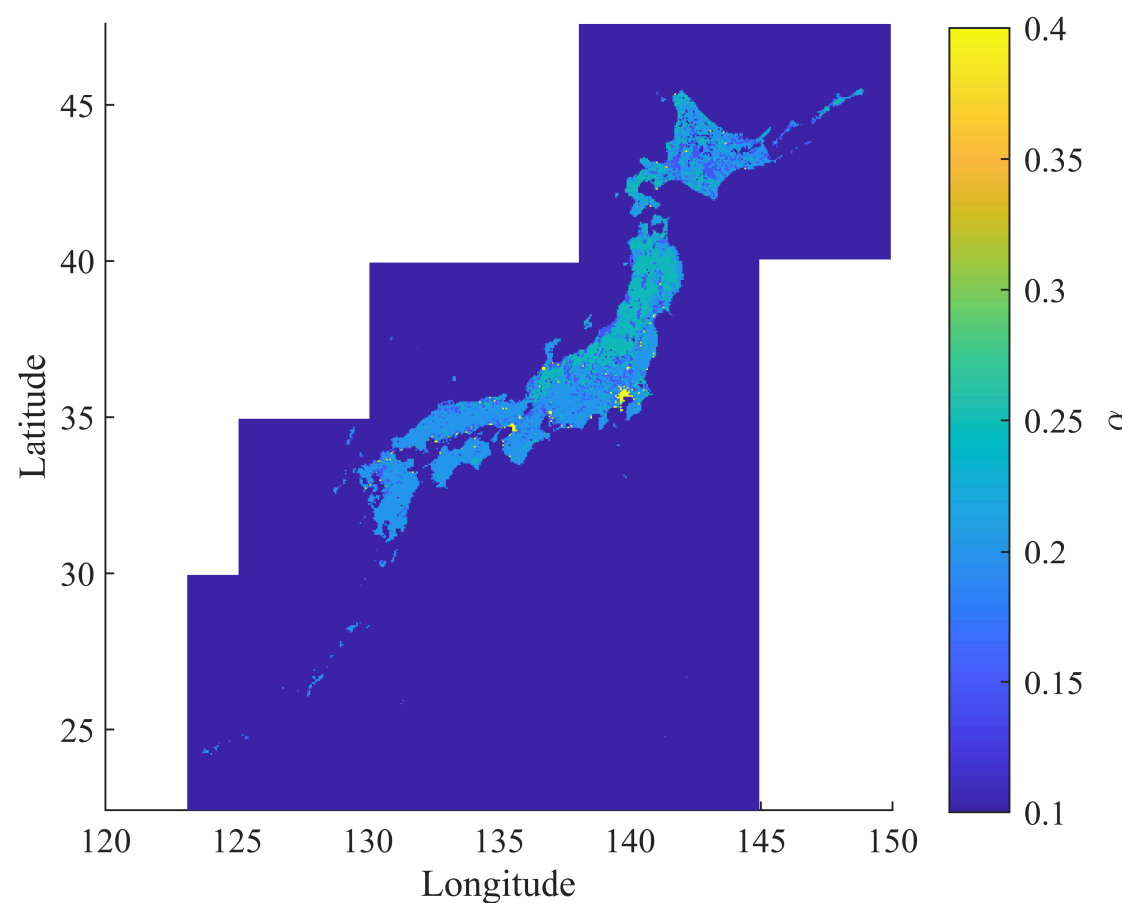

Figure 1. Map of $\alpha$ values used for the wind gradient estimation. (Color online.)

Finally, the wind speed is converted to energy potential $P$ in watts using the theoretical formula

$$
P=\frac{1}{2} \rho A v^{3} C_{p},
$$

with $A$ being the area covered by the rotors with length $r$ of the theoretical wind turbines, $C_{p}$ the coefficient of performance, and $\rho$ the air density taken constant and equal to $1.23 \mathrm{~kg} / \mathrm{m}^{3}$.

We consider different wind turbines for the onshore and offshore area, which parameters are summarized in Table 2, resulting in power curves shown in Figure 2. The rotors' length and coefficients of performance were selected to reach realistic rated powers while keeping realistic dimensions with respect to currently commercialized onshore and offshore types wind turbine models [29,30]. The offshore area is defined as the water bodies area in the land cover data, which includes large onshore lakes (larger than $5 \mathrm{~km}^{2}$ ). 


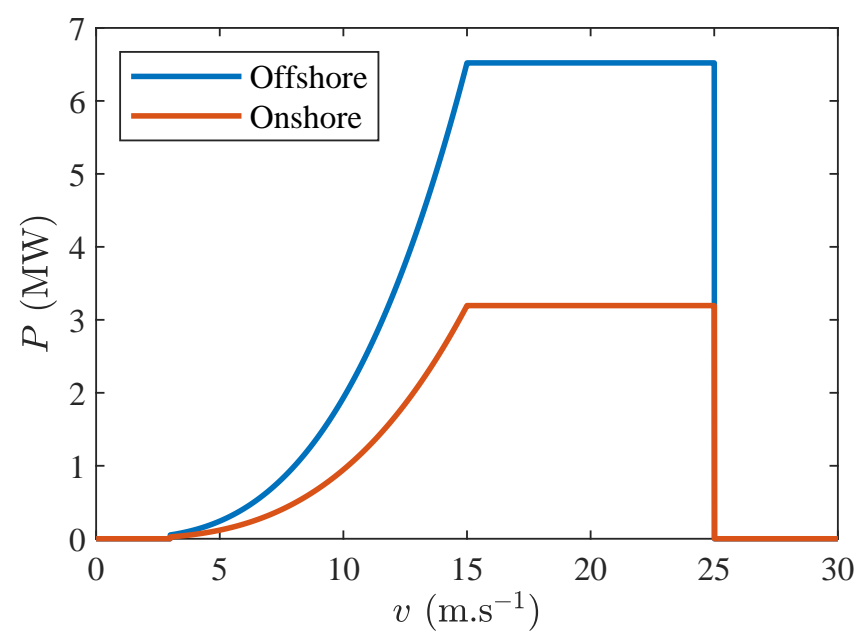

Figure 2. Power curves for the considered offshore and onshore theoretical wind turbines.

Table 2. Theoretical wind turbines parameters.

\begin{tabular}{lccc}
\hline & Onshore & Offshore & Units \\
\hline Cut-in speed & 3 & 3 & $\mathrm{~m} \cdot \mathrm{s}^{-1}$ \\
Rated speed & 15 & 15 & $\mathrm{~m} \cdot \mathrm{s}^{-1}$ \\
Cut-out speed & 25 & 25 & $\mathrm{~m} \cdot \mathrm{s}^{-1}$ \\
$h$ & 75 & 100 & $\mathrm{~m}$ \\
$r$ & 35 & 50 & $\mathrm{~m}$ \\
$C_{p}$ & 0.4 & 0.4 & 1 \\
\hline
\end{tabular}

\subsection{Analysis Methodology}

The spatial-temporal continuity and high resolution of these data allow for detailed analysis and visualization, such as the correlation of wind potential temporal fluctuations between sites, which was so far limited to sparse onshore data or spatially rough offshore estimates.

However, when analyzing the benefits of cross-region sharing from the estimated wind energy potential and actual electricity demand, it is necessary to define demand area based on governmental borders. Currently, available energy demand data with similar hourly time resolution only consists of the electricity demand per region from the major electric power supply companies [31].

The offshore area is limited to less than $30 \mathrm{~km}$ distance from coast and $200 \mathrm{~m}$ depth, and excludes marine park areas [32] granted that they have a non-negligible size compared with the meshes. Each mesh is allocated to the closest region calculated from the great-circle distance given by the Haversine formula

$$
d=2 R \arcsin \left(\sqrt{\sin ^{2}\left(\frac{\varphi_{m}-\varphi_{b}}{2}\right)+\cos \varphi_{b} \cos \varphi_{m} \sin ^{2}\left(\frac{\lambda_{m}-\lambda_{b}}{2}\right)}\right),
$$

with $R$ the earth average radius equal to $6371 \mathrm{~km},\left(\varphi_{m}, \lambda_{m}\right)$ the longitude and latitude coordinates of the meshes center, and $\left(\varphi_{b}, \lambda_{b}\right)$ the coordinates of the vertexes along each region borders. The considered onshore and offshore areas, as well as the meshes allocation result, are shown in Figure 3. Disputed territories are not included. 


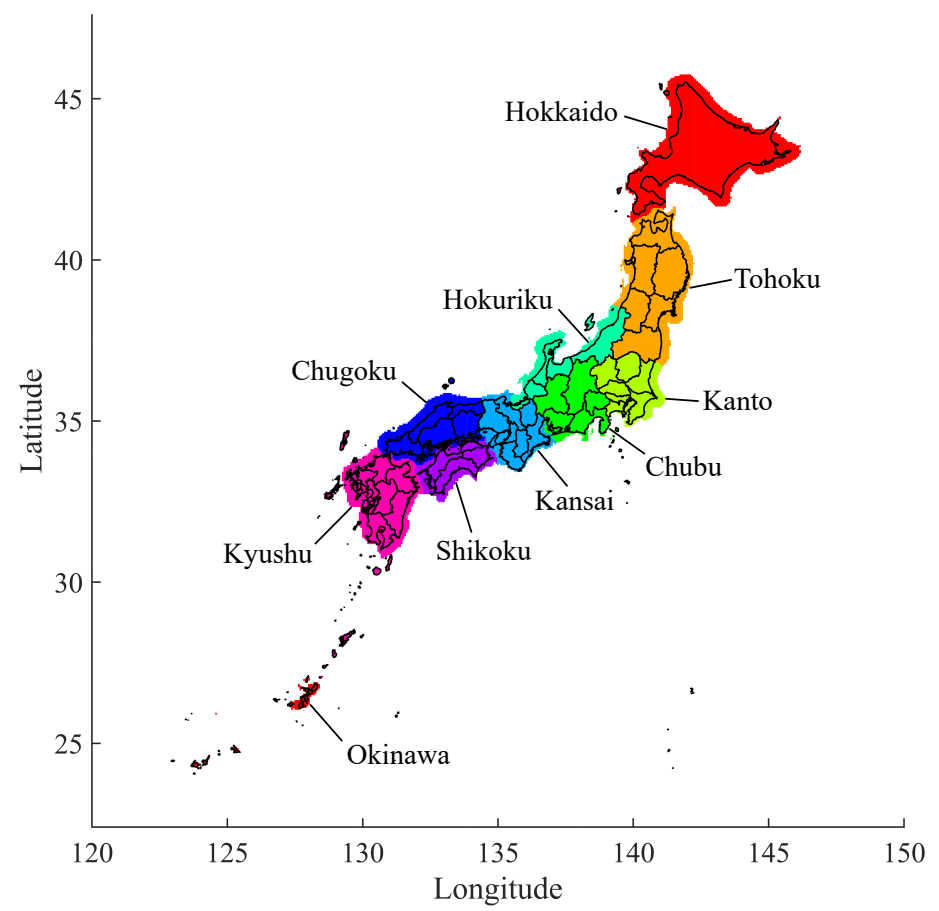

Figure 3. Potential sites for wind turbines installation and allocation to each Japan regions. (Color online.)

\section{Results and Discussion}

\subsection{Spatial-Temporal Wind Potential}

To demonstrate the accuracy of the data used in this study, we compare the average wind speed per hour estimated at $140 \mathrm{~m}$ altitude from 2007 to 2020 with the currently accepted data used by the Japanese Ministry of Environment at the same altitude covering the period from 1995 to 2014 [32,33]. Although the time spans are different, we assume that the respective periods of 13 years and 19 years are long enough with respect to the typical wind speed stochastic fluctuations, and that the impact of climate change on wind in Japan between 1995-2006 and 2016-2020 periods have a small enough effect on the total average. Figure 4 shows this average wind speed map which is similar to the current estimations.

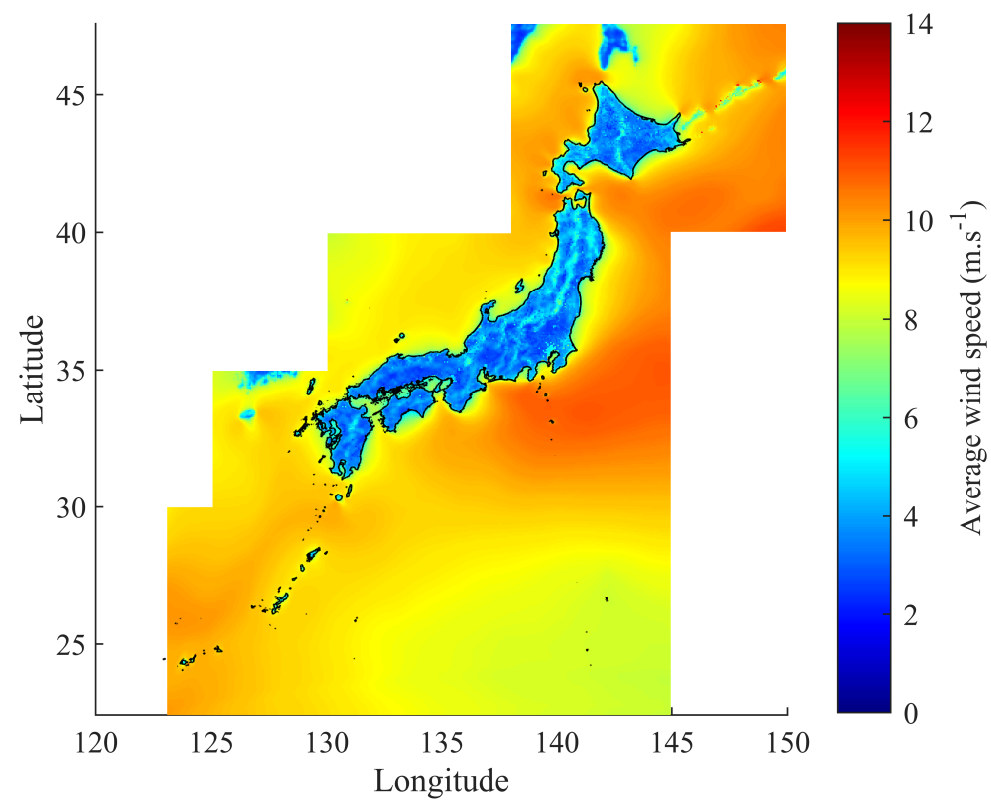

Figure 4. Average wind speed per hour at $140 \mathrm{~m}$ over the $2007-2020$ period. (Color online.) 
Figure 5 shows an example of the wind energy potential map on the day of 13 August 2019 at 11 a.m. with the typhoon Krosa of that year. The colors are displayed following a 1/3 power law to compensate the cubic value of wind speed in equation 3 and better distinguish zero from non-zero values. One can notice the energy potential dropping to zero between the typhoon eye and borders due to the wind speed exceeding the cut-off value of $25 \mathrm{~m} \cdot \mathrm{s}^{-1}$. The spatial-temporal evolution for 2019 is available in video format as a supplementary material.

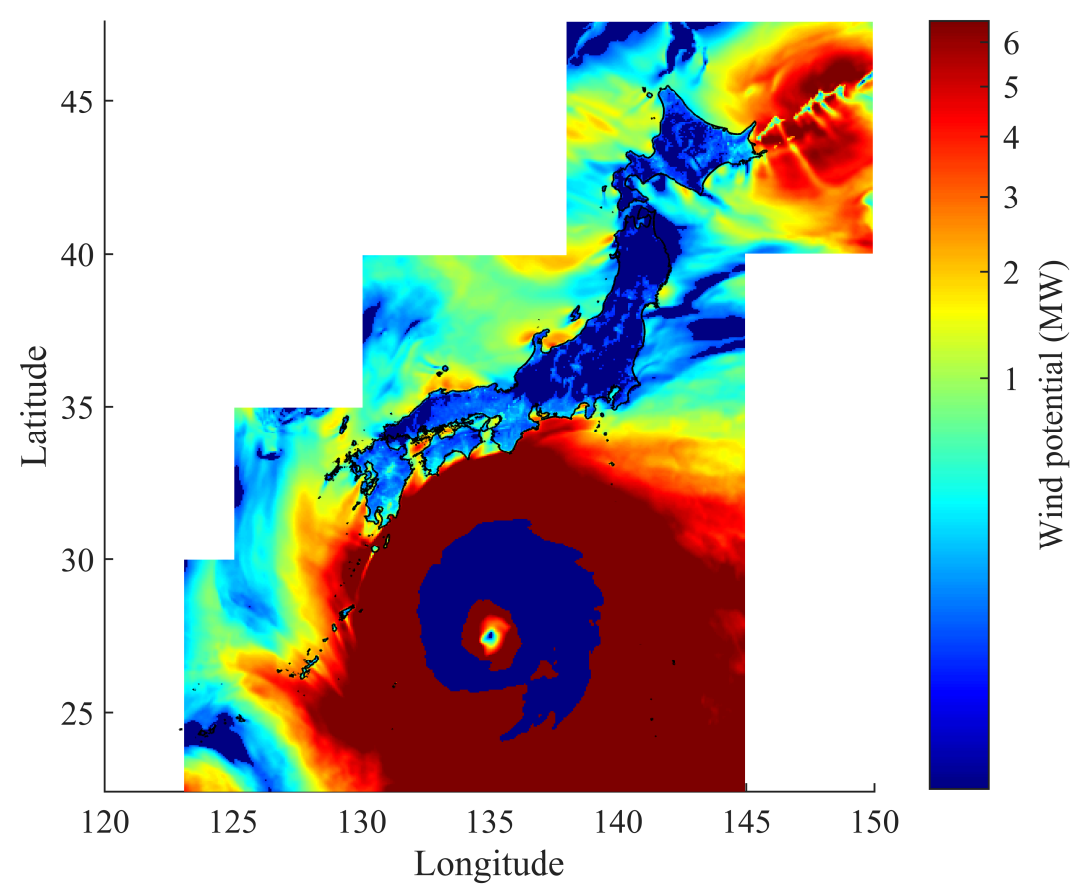

Figure 5. Wind energy potential on 13 August 2019 at 11 a.m. showing the typhoon Krosa of that year. (Color online.)

\subsection{Cross-Region Sharing Benefits Analysis}

Using the estimated data, we analyze the potential benefits of Japan's characteristic climate diversity for the stabilization of wind power generation and the ability to satisfy the not less diverse regions' electricity demand.

Figure 6 shows the probability distributions of the individual meshes wind energy potential limited to the onshore and offshore area defined in part 2.2 compared with the total potential distributions over the year 2019. The time-series are normalized by their maximum values rather than the rated powers as for the capacity factor, which could statistically never reach $100 \%$ in the total cases. One can see that the individual meshes energy potential oscillates between their minimum 0 and local maximum 1 , with few low intermediate values following a power decay fashion. This could translate into either a lack or an excess of power generation resulting in the turbines' curtailment without considering interconnections. Note also that onshore potential consists mainly of 0 with rare occurrences of the local maximum values. However, he total potential shows drastically reduced occurrences of these extremes, allowing the effective mitigation of both lack and excess production for a more stable supply. Notably, the total onshore potential, while still low, allows for constant positive power generation. 
a) Onshore

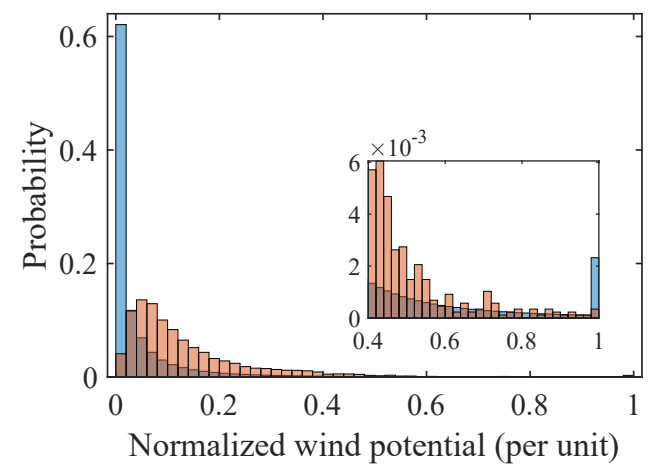

b) Offshore

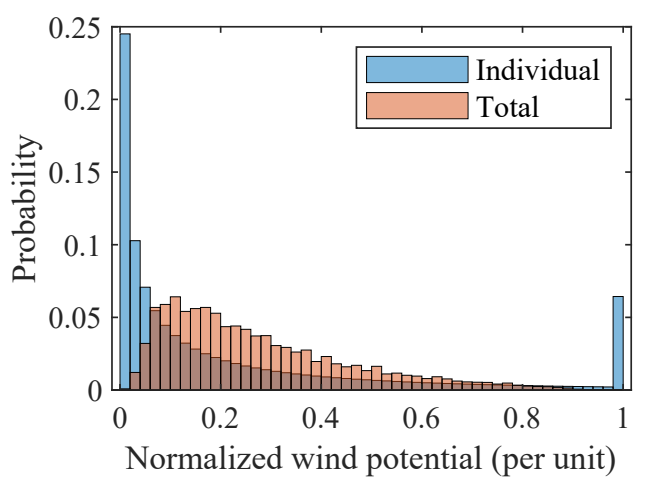

Figure 6. Probability distributions of normalized wind energy potential for (a) onshore, (b) offshore area.

To verify this mitigation of lack and excess production, we compare the hourly potential power production with the electricity demand data of 2019 [31]. Figure 7 shows the relative hourly difference between wind power supply and electricity demand for each region organized in descending order assuming one wind turbine per $\mathrm{km}^{2}$. The difference is calculated as

$$
\text { Relative electricity balance }=\frac{\text { Potential }- \text { Demand }}{\text { Demand }} .
$$

Both onshore and offshore area are considered here but onshore has a negligible effect on the results as one can judge from Table 3 summarizing the total potentials for each region in 2019.

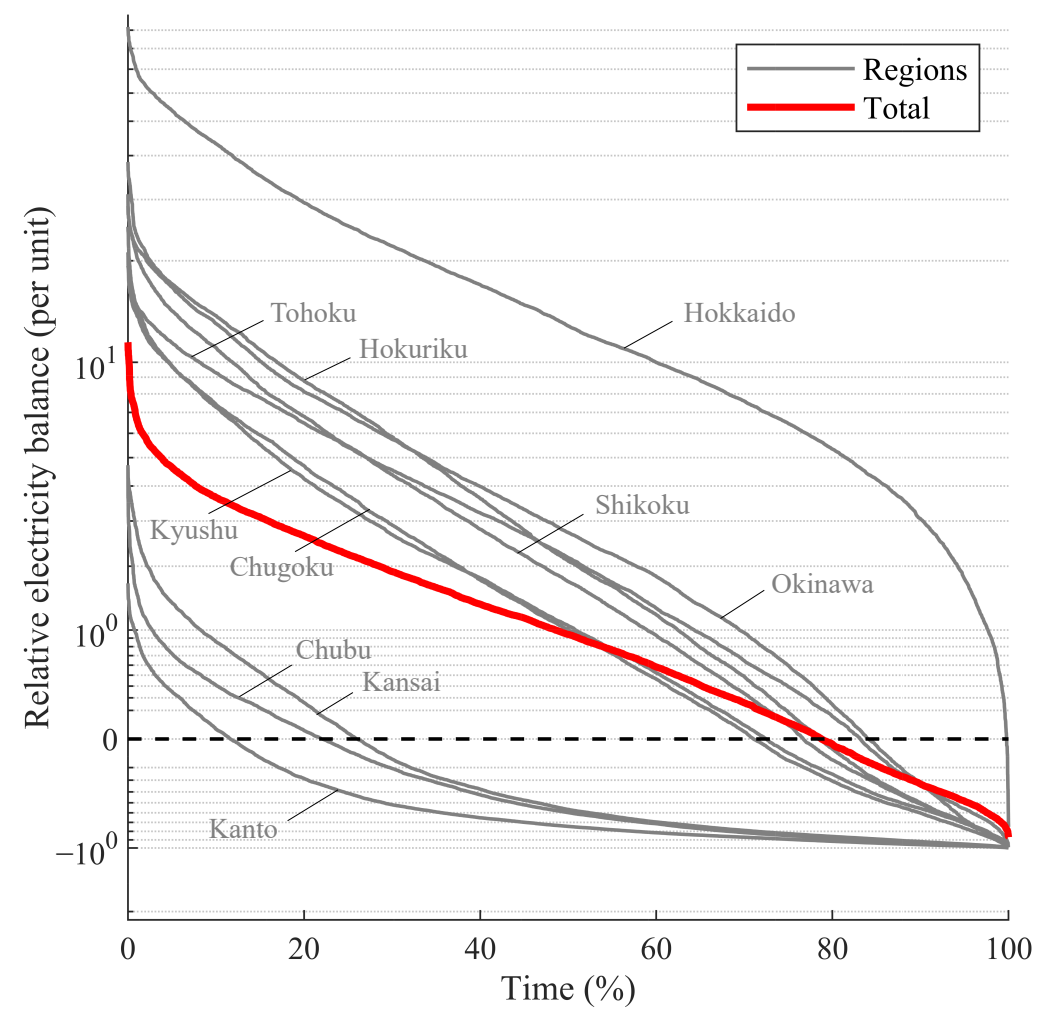

Figure 7. Per region and total relative electricity balance over time in 2019 sorted by descending order values. 
Table 3. Theoretical total wind energy potential compared with actual electricity demand per region in 2019.

\begin{tabular}{lccc}
\hline & Offshore (TW) & Onshore (TW) & Demand (TW) \\
\hline Hokkaido & 541.9 & 59.8 & 30.5 \\
Tohoku & 315.2 & 50.9 & 81.7 \\
Kanto & 99.3 & 15.6 & 285.3 \\
Chubu & 60.4 & 18.2 & 134.2 \\
Hokuriku & 144.7 & 18.9 & 29.2 \\
Kansai & 90.1 & 13.9 & 144.6 \\
Chugoku & 185.4 & 13.5 & 60.2 \\
Shikoku & 112.9 & 9.1 & 27.0 \\
Kyushu & 238.9 & 31.6 & 84.7 \\
Okinawa & 35.6 & 7.7 & 8.1 \\
\hline Total & 1824.4 & 239.2 & 885.5 \\
\hline
\end{tabular}

Three groups can be identified here. Kanto, Kansai, and Chubu, the most highly populated regions, have a positive electricity balance for around $20 \%$ of the time. Hokkaido, on the opposite end, stands out from the other regions with a significant positive electricity balance over $99 \%$ of the time due to its vast, primarily unoccupied area having a high wind potential. The remaining regions show a positive electricity balance around $80 \%$ of the time. The lack of power supply never not exceed one time the demand for all regions while the excess production can reach ten times or even a hundred times the local electricity demand in Hokkaido. The total energy balance indicates that sharing wind resources on a national scale can effectively mitigate power generation instabilities. It allows to maintain a power supply $80 \%$ of the time while still significantly reducing the excess production.

These results point toward the theoretical possibility of Japan energy systems having electricity supply based on wind resources exclusively (granted the integration of storage devices), even with smaller installed capacity, and despite the very restrictive offshore area, as well as the relatively low rated powers, compared with emerging more efficient turbines [30]. Moreover, one could expect that a non-homogeneous, smarter capacity spatial distribution would match if not further improve the generation stability with smaller total installed capacity. In the following, we analyze the importance of each site to support this capacity allocation problem.

\subsection{Sites Importance}

The stabilization of wind power generation through large scale sharing results from the production fluctuations of local sites decorrelating with distance. For this reason, many studies try to evaluate the typical correlation length using decay models [11].

Figure 8 shows an example of this wind potential correlation decay in Japan from a reference site placed offshore indicated by a cross. The Pearson correlation is used here with eventual negative values set as zero. In Figure 8a, one can see that sites close to the reference site tend to be highly correlated with it while farther sites increasingly loose correlation. However, this correlation is not equally distributed in space as assumed in the correlation length calculations, which solely consider the distance between sites. Some sites close to the reference one appear indeed less correlated to it than others farther away. The decay seems influenced by the nature of the terrain, such as mountains or water bodies. This is not caused by the potential estimation method as the Pearson correlation includes a normalization of the data and similar observations were made on the original wind speed data.

Figure $8 \mathrm{~b}$ shows the corresponding correlation probability distribution, excluding the reference self-correlation value of 1 . As a result of the overall correlation exponential decay with distance, the distribution appears skewed with its peak on the left of the mean. Since the stabilization of global power generation directly results from the correlation exponential decay with distance causing the skewness of its probability distribution, we 
introduce the skewness coefficient as a measure to quantify the sites' importance toward an efficient temporal smoothing. It can be defined as

$$
s=\frac{E(c-\bar{c})^{3}}{\sigma^{3}},
$$

with $E(x)$ the expected value of $x, c$ the correlation values excluding the reference selfcorrelation, and $\sigma$ the standard deviation of $c$. A negative skewness indicates that the values distribution's peak is right to the mean or that the distribution is skewed to the left, which is not expected in the present case. A zero skewness indicates a symmetrical distribution. A positive skewness indicates that the values distribution's peak is left to the mean or that the distribution is skewed to the right. For example, the skewness of an exponential probability density function is equal to 2 .

a) Spatial correlation decay with distance

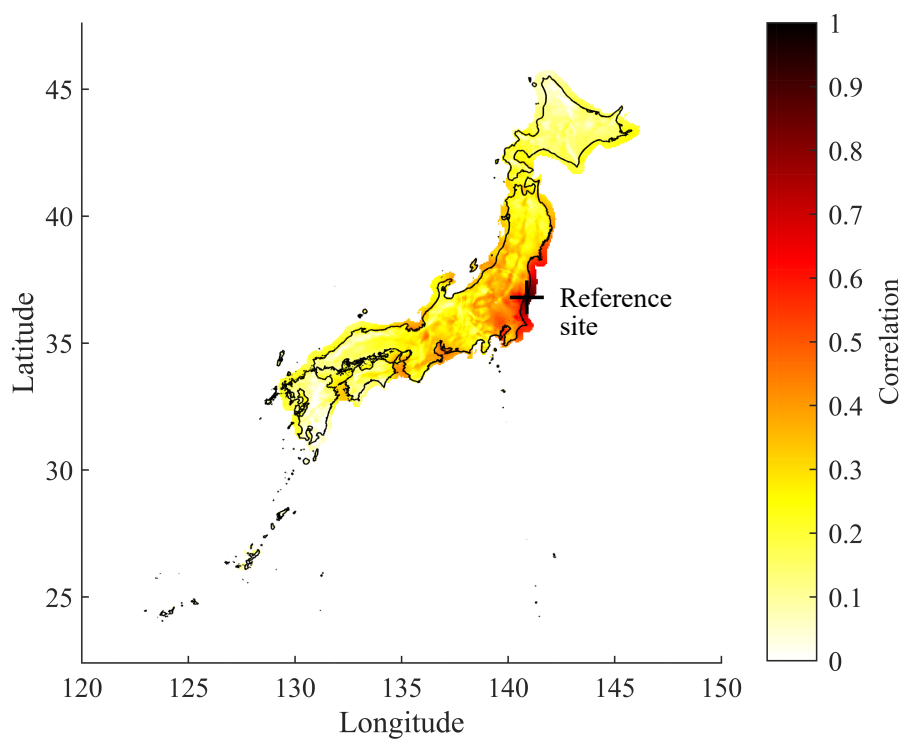

b) Correlation probability distribution

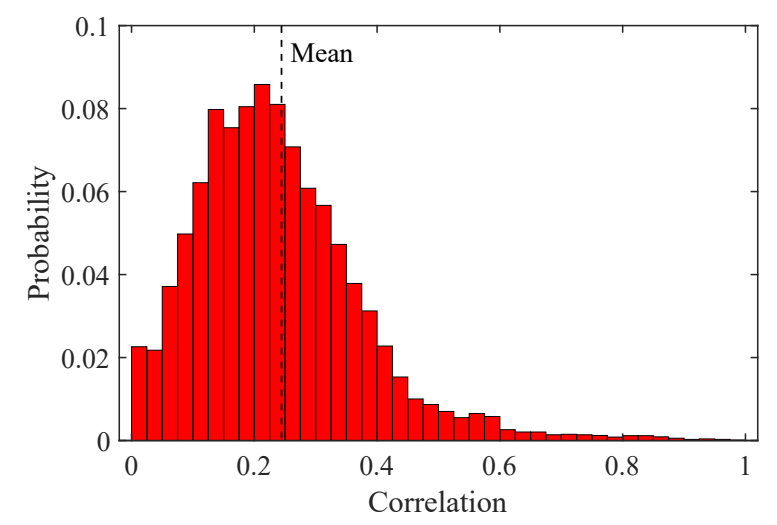

Figure 8. Example of wind power production spatial correlation with the reference site indicated by a cross in $(\mathbf{a}, \mathbf{b})$ the corresponding probability distribution.

The higher the skewness, the more sites are weakly or uncorrelated with the reference site. This measure can then be interpreted as a quantification of the sites' uniqueness among all potential sites and offers several advantages. It can be calculated directly from the data without prior assumptions, contrary the correlation length which rely on decay models. Furthermore, while the correlation length should be similar for all sites, the correlation 
skewness depends on the correlation between actually available sites, accounting for their location with respect to the global territory rather than the distance between them.

Figure 9 shows the correlation skewness map for the year 2019. With no surprise, the Okinawa region has the highest values due to its most isolated location. High correlation skewness can also be found at the two extremes of Japan, near southern Kyushu and northern Hokkaido, for the same reason. Less trivially, the Kanto region, western Hokuriku, and northern Chugoku also appear to be poorly correlated with other locations. These regions should play a significant role in the temporal smoothing of wind power generation.

Because the correlation calculation gives information on the potential fluctuations only, we also compute the average energy potential as shown in Figure 10. Except for western Hokuriku, the offshore part of identified regions with high correlation skewness also appear to have a high energy potential. Although showing small correlation skewness values, the offshore northern area of Tohoku stands out with the highest energy potential. These results were confirmed to be consistent with different years.

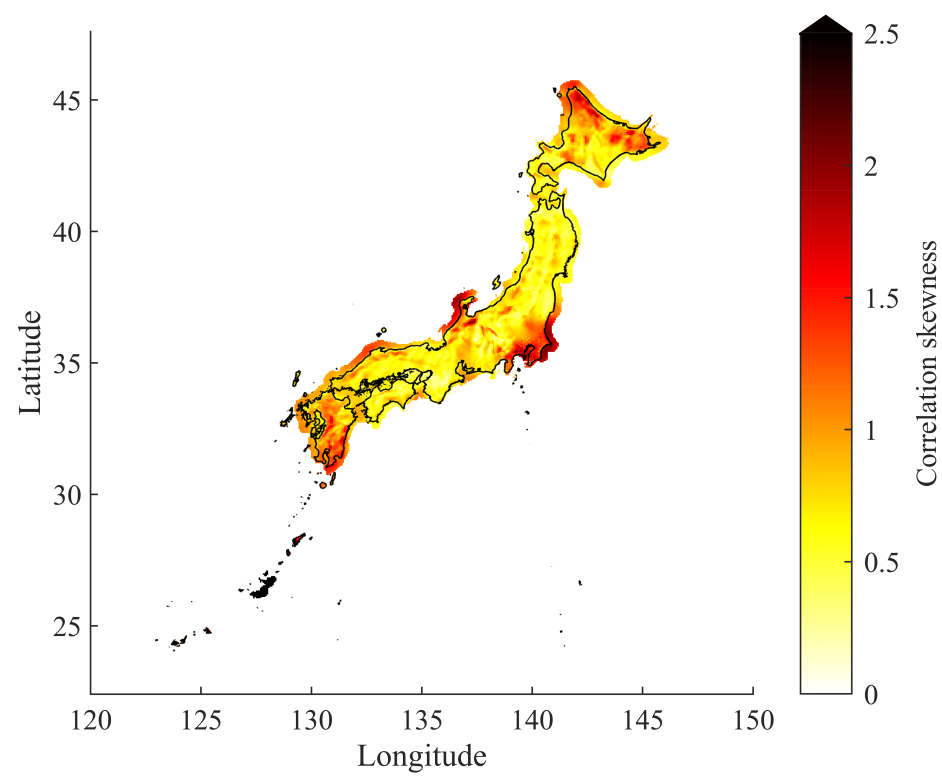

Figure 9. Correlation skewness coefficient map for the year 2019. Similar results were obtained for different years.

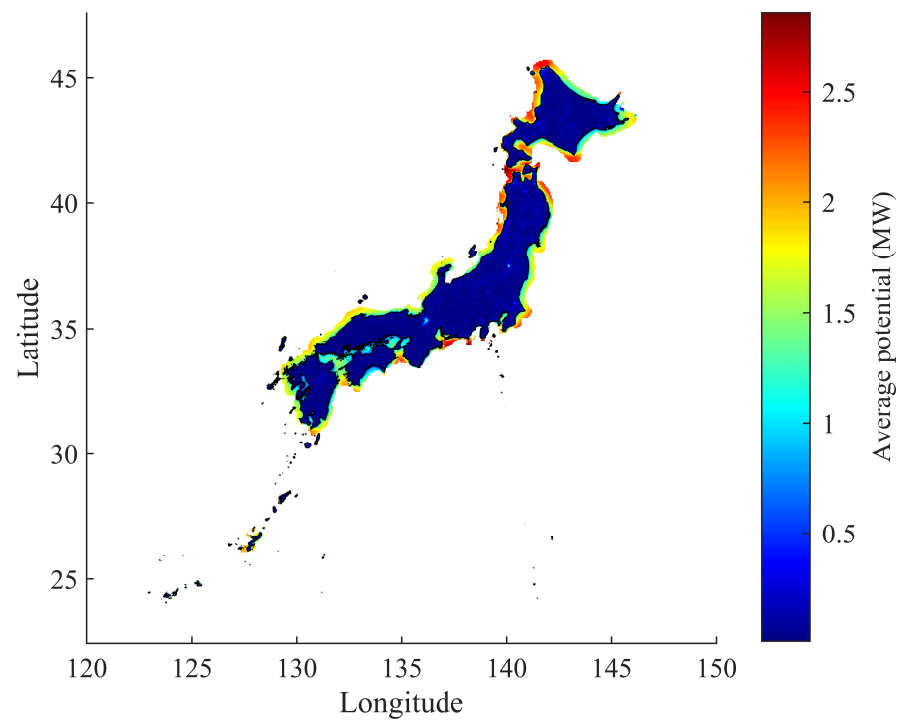

Figure 10. Average potential wind power production (per hour) over the year 2019. Similar results were obtained for different years. (Color online.) 


\section{Summary}

The instability of energy production from wind and solar renewable resources can be mitigated through cross-region sharing on large scales between European countries or American states in low-carbon emissions scenarios. Japan, on the other hand, must primarily rely on its local resources. While its high wind energy potential has been demonstrated, studies accounting for the spatial-temporal wind variations have been limited by the lack of data with sufficient spatial or temporal resolution, especially offshore due to the lack of sensors. The present study aimed at filling this lack and analyze the self-sustainability potential of this geographically isolated country with a great diversity of climates and frequent extreme weather events.

Based on past meteorological data from the local national agency, the wind energy potential was estimated with high spatial and temporal resolution. From this estimation, we could demonstrate the effectiveness of wind resources global sharing in Japan for mitigating both under-supply and over-supply resulting in turbines curtailment. Theoretically, it was confirmed that past electricity demand could be satisfied by wind power around $80 \%$ of the time despite the restricted considered area and turbines efficiency, which could be further extended with the integration of storage devices and smarter capacity spatial distribution. Although the onshore wind potential estimation could be improved by applying land suitability factors for each region, its potential is negligible compared with offshore and should not impact the conclusions. Finally, defining the correlation skewness as a measure for quantifying the uniqueness of sites' power generation fluctuations allowed us to identify important regions toward the stabilization of global power generation, which should help in the capacity allocation problem.

Future research directions include considerations on wind direction [34,35], more accurate wind gradient estimation including seasonal terrain variations and from on-site measurements, paired analysis with solar resources, the capacity allocation for efficient and resilient supply, and scenario analysis using past wind data with prospected future electricity demand.

Supplementary Materials: The following are available online at https:/ / www.mdpi.com/1996-107 3/14/8/2168/s1, Video S1: Spatial-temporal evolution of wind potential in 2019.

Author Contributions: Conceptualization, R.D.; methodology, R.D.; software, R.D. and T.M.; validation, R.D.; formal analysis, R.D. and T.M.; investigation, R.D. and T.M.; resources, T.N.; data curation, R.D.; writing—original draft preparation, R.D.; writing—review and editing, T.N.; visualization, R.D. and T.M.; supervision, R.D. and T.N.; project administration, R.D. and T.N.; funding acquisition, T.N. All authors have read and agreed to the published version of the manuscript.

Funding: This work was supported by Council for Science, Technology and Innovation (CSTI), Cross-ministerial Strategic Innovation Promotion Program (SIP), “Energy systems of an Internet of Energy (IoE) society" (Funding agency: JST).

Acknowledgments: We thank Tetsushi Amano for informing us on the meteorological data archives used in this study.

Conflicts of Interest: The authors declare no conflict of interest.

\section{References}

1. Nakata, T. Energy-economic models and the environment. Prog. Energy Combust. Sci. 2004, 30, 417-475. [CrossRef]

2. Markard, J. The next phase of the energy transition and its implications for research and policy. Nat. Energy 2018, 3, 628-633. [CrossRef]

3. Behrangrad, M. A review of demand side management business models in the electricity market. Renew. Sustain. Energy Rev. 2015, 47, 270-283. [CrossRef]

4. Roozbehani, T.; Dahleh, M.A.; Mitter, S.K. Volatility of Power Grids Under Real-Time Pricing. IEEE Trans. Power Syst. 2012, 27, 1926-1940. [CrossRef]

5. Peters, J.F.; Baumann, M.; Zimmermann, B.; Braun, J.; Weil, M. The environmental impact of Li-Ion batteries and the role of key parameters-A review. Renew. Sustain. Energy Rev. 2017, 67, 491-506. [CrossRef] 
6. $\quad$ Robinius, M.; Otto, A.; Heuser, P.; Welder, L.; Syranidis, K.; Ryberg, D.; Grube, T.; Markewitz, P.; Peters, R.; Stolten, D. Linking the power and transport sectors-Part 1: the principle of sector coupling. Energies 2017, 10, 956. [CrossRef]

7. Brown, T.; Schlachtberger, D.; Kies, A.; Schramm, S.; Greiner, M. Synergies of sector coupling and transmission reinforcement in a cost-optimised, highly renewable European energy system. Energy 2018, 160, 720-739. [CrossRef]

8. Maruf, M.N.I. Sector coupling in the north sea region-A review on the energy system modelling perspective. Energies 2019, 12, 4298. [CrossRef]

9. Rodriguez, R.A.; Becker, S.; Andresen, G.B.; Heide, D.; Greiner, M. Transmission needs across a fully renewable European power system. Renew. Energy 2014, 63, 467-476. [CrossRef]

10. Neuhoff, K.; Bach, S.; Diekmann, J.; Beznoska, M.; El-Laboudy, T. Distributional effects of energy transition: impacts of renewable electricity support in Germany. Econ. Energy Environ. Pol. 2013, 2, 41-54. [CrossRef]

11. Martin, C.M.S.; Lundquist, J.L.; Handschy, M.A. Variability of interconnected wind plants: correlation length and its dependence on variability time scale. Environ. Res. Lett. 2015, 10, 044004. [CrossRef]

12. Bale, C.S.E.; Varga, L.; Foxon, T.J. Energy and complexity: New ways forward. Appl. Energy 2015, 138, 150-159. [CrossRef]

13. Alestone, P.; Gerhenson, D.; Kammen, D.M. Decentralized energy systems for clean electricity access. Nat. Clim. Chang. 2015, 5, 305-314. [CrossRef]

14. Morstyn, T.; Farrell, N.; Darby, S.J.; McCulloch, M.D. Using peer-to-peer energy-trading platforms to incentivize prosumers to form federated power plants. Nat. Energy 2018, 3, 94-101. [CrossRef]

15. Delage, R.; Nakata, T. Machine learning for modeling energy systems complexity. In Proceedings of the 33rd International Conference on Efficiency, Cost, Optimization, Simulation and Environmental Impact of Energy Systems, Osaka, Japan, 29 June-3 July 2020; pp. 2405-2414.

16. IEA. Japan 2021, IEA, Paris. 2021. Available online: https:/ /www.iea.org/reports/japan-2021 (accessed on 11 March 2021).

17. Fujii, T.; Henderson, A.R.; Leuts, R. Potential for Floating Offshore Wind Energy in Japanese Waters. In Proceedings of the ISOPE 2002: Kitakyushu, Japan, 26-31 May 2002.

18. Esteban, M.; Portugal-Pereira, J.; Mclellan, B.C.; Bricker, J.; Farzaneh, H.; Djalilova, N.; Ishihara, K.N.; Takagi, H.; Roeber, V. 100\% renewable energy system in Japan: Smoothening and ancillary services. Appl. Energy 2018, 224, 698-707. [CrossRef]

19. Yamaguchi, A.; Ishihara, T. Assessment of Offshore Wind Energy Potential Using Mesoscale Model and Geographic Information System. Renew. Energy 2014, 69, 506-515. [CrossRef]

20. Bardenhagen, Y.; Nakata, T. Regional Spatial Analysis of the Offshore Wind Potential in Japan. Energies 2020, 13, 6303. [CrossRef]

21. Bett, P.E.; Thornton, H.E. The climatological relationships between wind and solar energy supply in Britain. Renew. Energy 2016, 87, 96-110. [CrossRef]

22. Earl, N.; Dorling, S.; Hewston, R.; von Glasow, R. 1980-2010 Variability in U.K. Surface Wind Climate. J. Clim. 2013, $26,1172-1191$. [CrossRef]

23. Japan Meteorological Agency: Outline of the Operational Numerical Weather Prediction. Available online: https://www.jma.go jp/jma/jma-eng/jma-center/nwp/outline2019-nwp/index.htm (accessed on 11 March 2021).

24. Kyoto University, Japan Meteorological Agency Data. Available online: http://database.rish.kyoto-u.ac.jp/arch/jmadata/ (accessed on 11 March 2021).

25. Gelaro, R.; McCarty, W.; Suárez, M.J.; Todling, R.; Molod, A.; Takacs, L.; Randles, C.; Darmenov, A.; Bosilovich, M.G.; Reichle, R.; et al. The Modern-Era Retrospective Analysis for Research and Applications, Version 2 (MERRA-2). J. Clim. 2017, 30, 5419-5454. [CrossRef]

26. Hersbach, H.; Bell, B.; Berrisford, P.; Hirahara, S.; Horányi, A.; Muñoz-Sabater, J.; Nicolas, J.; Peubey, C.; Radu, R.; Schepers, D.; et al. The ERA5 global reanalysis. Q. J. R. Meteorol. Soc. 2020, 146, 1999-2049. [CrossRef]

27. Banuelos-Ruedas, F.; Angeles-Camacho, C.; Rios-Marcuello, S. Analysis and validation of the methodology used in the extrapolation of wind speed data at different heights. Renew. Sustain. Energy Rev. 2010, 14, 2383-2391. [CrossRef]

28. Geospatial Information Authority of Japan, Global Map Japan. Available online: https://www.gsi.go.jp/kankyochiri/gm_japan_ e.html (accessed on 11 March 2021).

29. Ziegler, L.; Gonzalez, E.; Rubert, T.; Smolka, U.; Melero, J.J. Lifetime extension of onshore wind turbines: A review covering Germany, Spain, Denmark, and the UK. Renew. Sustain. Energy Rev. 2018, 82, 1261-1271. [CrossRef]

30. IEA-International Energy Agency. Offshore Wind Outlook 2019: World Energy Outlook Special Report; IEA: Paris, France, 2019.

31. Institute for Sustainable Energy Policies, Electricity Generation and Demand. Available online: https://isep-energychart.com/ en/graphics / (accessed on 11 March 2021).

32. Japan Ministry of the Environment, REPOS. Available online: http:/ / www.renewable-energy-potential.env.go.jp/RenewableEnergy / 21.html (accessed on 11 March 2021).

33. NeoWins (NEDO Offshore Wind Information System). Available online: http://app10.infoc.nedo.go.jp/Nedo_Webgis/index. html (accessed on 11 March 2021).

34. Castellani, F.; Astolfi, D.; Garinei, A.; Proietti, S.; Sdringola, P.; Terzi, L.; Desideri, U. How Wind Turbines Alignment to Wind Direction Affects Efficiency? A Case Study through SCADA Data Mining. Energy Procedia 2015, 75, 697-703. [CrossRef]

35. Husaru, D.E.; Barsanescu, P.D.; Zahariea, D. Effect of yaw angle on the global performances of Horizontal Axis Wind TurbineQBlade simulation. IOP Conf. Ser. Mater. Sci. Eng. 2019, 595, 012047. [CrossRef] 